\title{
Economic, Agronomic, and Environmental Benefits From the Adoption of Precision Agriculture Technologies:
} A Systematic Review Thomas Koutsos, School of Agriculture, Faculty of Agriculture, Forestry, and Natural Environment, Aristotle University of
Thessaloniki, Thessaloniki, Greece

Georgios Menexes, School of Agriculture, Faculty of Agriculture, Forestry, and Natural Environment, Aristotle University of Thessaloniki, Thessaloniki, Greece

\begin{abstract}
Precision agriculture (PA) as an integrated information- and production-based farming system is designed to delivery high-end technology solutions to increase farm production efficiency and profitability while minimizing environmental impacts on the ecosystems and the environment. PA technologies are technology innovations that incorporate recent advances in modern agriculture providing evidence for lower production costs, increased farming efficiency and reduced impacts. However, the adoption of the precision agriculture technologies has encountered difficulties such as additional application or management costs and investment on new equipment and trained employees. Some of these PA technologies were proven efficient, providing tangible benefits with lower costs and as a result they quickly gained scientific interest. To investigate further the economic, agronomic, and environmental benefits from the adoption of PA technologies a systematic review was conducted, based on the systematic search and evaluation of related eligible articles.
\end{abstract}

\section{KEYWORDS}

Environmental Protection, Farming Efficiency, Innovations in Agriculture, Precision Agriculture

\section{INTRODUCTION}

The world's growing demand for food in the long term (Baudron \& Giller, 2004) has raised the concern of our ability to meet this need without putting enormous pressure on the world's natural resources and causing environmental damage. Climate change will also greatly impact food supply and demand and tougher environmental conditions, while anticipated resource limitations and increased production costs are putting constantly pressure on crop production systems. The challenge of the adoption of precision agriculture technologies seems to be a 'One-way road' to increase farming efficiency while minimizing environmental impacts (Awan, 2016; Foley et al., 2011).

For the last two decades, technological innovations have been tested to improve farming efficiency and reduce environmental impact (Daberkow \& McBride 2003; Robertson et al. 2012; Tey \& Brindal 
2012). However, in the beginning, increased implementation costs had limited or uncertain benefits that lead more farmers to be unwilling to adopt available PA technologies on their farms (Castle et al., 2016). Recent studies (Liu et al., 2017; Nawar et al., 2017) on PA technologies indicated that the adoption of this technology can offer increased yields and productivity and also economic returns from reduced agricultural inputs limiting the excessive use of agro-chemicals in accordance with the latest environmental legislation. Individual studies (Calegari et al., 2013; Jayakumar et al., 2017; West and Kovacs, 2017) also focused and demonstrated the economic (monetary), agronomic (yield increase) and environmental benefits (reduction of negative impacts) of adopting PA technologies. These research findings on how data derived from soil characteristics, plant populations and environment can be organized to deliver targeted input applications to crop production systems encourage farmers to step into the new era of digital agriculture (Panagopoulos et al., 2014; West and Kovacs, 2017; Nawar et al., 2017).

In the traditional farm management model each field is treated as a homogeneous area (Srinivasan, 2006), where soil, topographic and environmental conditions are considered to be similar and the inputs are applied uniformly regardless any potential variability or heterogeneity. This approach leads to unwanted explicit economic costs due to inefficient application of inputs, causing also environmental damage due to the surplus of the unused nutrients (up to $30 \%$ of total $\mathrm{N}$ ) that end up to ecosystems and the environment through leaching of water-soluble nitrates (Meisinger \& Delgado, 2002), or runoff and gaseous emissions that increase the contamination risk (Follett \& Delgado 2002; Hyytiainen et al., 2011; Rodriguez et al., 2011). In this case, the adoption of PA technologies can deliver a more efficient application of inputs under different conditions (Pierpaoli et al., 2013) or apply a single rate of a specific crop input to attain maximum efficiency (Vrindts et al., 2015) to sub-regions of broad similarity, defined as management zones, which regularly provide low or high yields (Fleming et al., 2004).

Criticism of the adoption of precision agriculture technologies has encompassed numerous arguments regarding the measurable benefits of adopting these new technologies (Basso et al. 2011; Stafford 2000,). In many cases, agronomic, economic and environmental benefits from the adoption of PA technologies indeed cannot be certain and they depend on several other factors, such as the farm size (bigger agricultural area income provides higher margin for new technology investments) or more dynamic variables, such the climate or soil conditions. However, many studies have successfully shown tangible benefits from the adoption of PA technologies (Basso et al., 2011; Boyer et al., 2011; Panagopoulos et al., 2014; West \& Kovacs, 2017).

To investigate the economic, agronomic and environmental benefits from the adoption of PA technologies a systematic review was conducted to analyze the last decade literature and provide useful insights and reveal trends. The main aim of this study was to highlight the PA technologies that provide the most measurable benefits and be can easily adopted to improve farm productivity and profitability, while minimizing environmental impacts.

\section{MATERIALS AND METHODS}

\section{Study Design}

For this systematic review a comprehensive protocol was developed and approved by all the authors. All steps for performing atypical systematic review were followed (Prisma, 2009): (1) scoping (development of a review protocol); (2) planning (development of the search strategy, selection of digital data sources); (3) identification/Searching (executing the search and check the resulted articles); (4) screening (management of citations and remove duplicates); (5) eligibility/Assessment (inclusion/exclusion criteria, quality assessment of the included articles and assessment of bias); and (5) presentation/interpretation (synopsis of findings, discussion and presentation of the results). 


\section{Focused Questions}

What are the expected economic, agronomic and environmental benefits from adopting different precision agriculture technologies? Which are the PA technologies that offer more tangible benefits? Can the adoption of PA technologies have a positive allocative and cost efficiency effect in agriculture while increasing productivity and farming efficiency? How can the adoption of technological innovations in agriculture contribute to the environmental protection and conservation?

\section{Search Strategies}

The advanced web-based search tools for developing small and effective SQL statements to query the three selected online digital sources for scientific articles were used to identify published studies that reported benefits from the adoption of PAtechnologies. A basic SQL query based on the search strategy was developed and a systematic search of three online digital scientific journal databases was performed: Web of Science, Scopus, and Science Direct to identify studies based on a combination of a group of terms. The search strategy terms for each journal database are given in detail at Table 1. The terms within each group were combined with 'OR', and three groups were linked with 'AND'. The full SQL query syntax used is shown in Table 1. Research articles resulting from the search process were examined based on the eligibility criteria set for this systematic review. In cases where the eligibility of a selected article could not be determined through titles and abstracts, a thorough review was carried out after reading in depth the full text of the study. For studies that met the given eligibility criteria, an additional search was performed for other relevant studies using Google Scholar. The process of checking the studies for eligibility and the final selection of the articles was performed by two independent reviewers and any dispute was resolved during a consensus debate with a third evaluator (Windt et al., 2000).

\section{Eligibility Criteria}

For the selection of articles, the following inclusion criteria were set: (1) Studies should have a purpose of examining the economic, agronomic or environmental benefits from the adoption of PA technologies; (2) all studies are published in peer-reviewed English language journals; (3) studies should reported results related to PA technologies. For the exclusion the following criteria were set: (1) studies which investigated the benefits from the adoption of PA technologies on a theoretical basis; (2) literature reviews, conference papers or symposiums; and (3) articles published before the year 2007 (although manually 16 studies were identified and added for eligibility).

Table 1. Search strategy. The search strategy was performed at first on February 11, 2017 to identify articles for initial screening. On April 25, 2017, the final search strategy was applied to screen to articles to be assessed in this systematic review.

1. Web of Science: $(\mathrm{N}=16)$ : $(\mathrm{TI}=$ (precision agriculture) AND TS $=$ (benefits) AND TS = (lower costs OR efficiency OR environment OR conservation OR protection OR risk OR economy OR effectiveness OR technology OR gains OR implications OR impacts)) AND LANGUAGE: (English) AND DOCUMENT TYPES: (Article) Indexes = SCI-EXPANDED, SSCI, A\&HCI, CPCI-S, CPCI-SSH, ESCI Timespan = 2007-2017.

2. Science Direct: ( $=19)$ : TITLE-ABS-KEY ("precision agriculture") AND TITLE-ABS-KEY ("benefits") AND TITLE-ABS-KEY ("costs") AND TITLE-ABS-KEY ("implications" OR "lower costs" OR "efficiency" OR “environment” OR “conservation" OR "protection" OR "risk" OR "economy” OR "crop quality” OR "food safety" OR "effectiveness" OR “technology" OR "mapping”).

3. Scopus: ( $=48$ ): (TITLE-ABS-KEY ("precision agriculture") AND TITLE-ABS-KEY ("benefits") AND TITLEABS-KEY (“costs") AND TITLE-ABS-KEY (("implications" OR "lower costs" OR "efficiency" OR "environment" OR "conservation" OR "protection" OR "risk" OR "economy" OR “crop quality" OR "food safety" OR "effectiveness" OR "technology” OR "mapping”))) AND PUBYEAR > 2006 AND (LIMIT-TO (SRCTYPE, “j “)) AND (LIMITTO (DOCTYPE, “ar “) OR LIMIT-TO (DOCTYPE, ” cp “) OR LIMIT-TO (DOCTYPE, "ar ")) AND (LIMIT-TO (LANGUAGE, "English ")) 


\section{Strength of Evidence}

The main concern during the process of identifying and assessing the eligible articles included in this systematic review was to find studies with proven economic, agronomic or environmental benefits. In some cases, the adoption of specific PA technologies, such as the variable rate technologies (VRT) can have direct benefits and monetary savings can be calculated. In other cases, the adoption of technology innovations in agriculture can have indirect benefits (minimized environmental risk by limiting crop inputs) that are difficult to be measured. Environmental gains have usually monetizing indirect benefits (i.e. from using remote sensing data) and it is complex and challenging to be assessed (Kalluri et al., 2003). For the assessment of studied included towards their strength of evidence for each category of benefits (economic, agronomic and environmental) four subgroups were formed with scaled strength of evidence (Table 2). After reading and checking all studies, all articles were assigned to one of these subgroups for each category of benefits. The goal of strength of evidence assessments was to provide clearly explained and well-reasoned judgments in this systematic review for the economic, agronomic and environmental benefits expected from the adoption of PA technologies.

For the economic assessment of the studies the following subgroups were formed based on the economic feasibility of the method used be each study: (1) partial budget or substantiated report (PB); (2) rough partial budget reports (RP) and (3) unsubstantiated reports (UR). For the assessment of studies, the following changes in costs were examined: (1) input costs; (2) application costs; (3) information or management costs; (4) equipment costs; (5) sampling costs (i.e. soil tests, mapping costs); (6) labor costs or any other custom cost type. Articles providing detailed partial budgets with documented positive changes in costs as economic benefits were labeled as "partial budget or substantial' reports. Articles reported changes in these costs but failed to enumerate a detailed economic analysis and specify monetary economic gains were labeled as "rough partial budget reports". Articles providing numerical estimates of changes in these costs suggesting generally that net returns were expected attributable to the adoption of a PA technology without providing monetary information about changes in costs and revenue were classified as "unsubstantiated reports". Finally, articles not providing any kind of economic information in change of costs are labeled as "not applicable".

Similarly, for the agronomic assessment of the studies on the farming efficiency, the following subgroups were used: (1) field trials (FT); (2) simulation models (SM) and (3) response functions (RF). All studies were examined in terms of the method they had reported. The above subgroups refer to methods used to mimic crop response under alternative agronomic practices. Field trials can be considered as experiments conducted on a smaller controlled area having the advantage of reflecting a broader range of yield limiting factors. Response functions (generally simple equations or computer simulations) are digital simulations that facilitate comparison between input changes or the cost of making these changes.

Finally, for the environmental assessment of the studies, the following subgroups were used to evaluate the environment benefits from the adoption of PA technologies at each study: (1) documented benefits (DB); (2) potential indirect environmental benefits (IB); and (3) unsubstantiated benefits. Articles providing detailed environmental gains were assigned to the first subgroup as having "documented benefits", articles that reported potential environmental benefits but failed to enumerate them were assigned as having "potential indirect environmental benefits" and articles reported environmental benefits generally without providing further information are labeled as having "unsubstantiated environmental benefits" (Table 2).

A simple yet effective system was developed for grading the quality (level) of evidence and the strength of recommendations of studies included in this systematic review to facilitate their critical appraisal (Table 2). Four levels of evidence were defined as follows: (1) strong evidence (S1): studies with consistent results of high quality, proven economic, agronomic or environmental benefits from the adoption of the proposed PA technology; (2) moderate evidence (S2): studies with consistent results with rough partial budget analysis or articles that use simulation methods; (3) some evidence (S3): studies with unsubstantiated benefits or recommendations regardless quality; Consistent results 
Table 2. Strategy for assigning strength of evidence (S) to the selected studies

\begin{tabular}{|l|l|l|l|}
\hline \multicolumn{1}{|c|}{$\begin{array}{c}\text { Strength of } \\
\text { Evidence }\end{array}$} & \multicolumn{1}{|c|}{ Economic } & \multicolumn{1}{c|}{ Agronomic } & \multicolumn{1}{c|}{ Environmental } \\
\hline $\begin{array}{l}\text { Strong evidence } \\
\text { (S1) }\end{array}$ & $\begin{array}{l}\text { Partial budget reports } \\
\text { or substantiated (PB) }\end{array}$ & $\begin{array}{l}\text { Field trials (FT) with } \\
\text { documented benefits }\end{array}$ & $\begin{array}{l}\text { Documented benefits (DB) } \\
\text { (i.e. reduction in nutrients, pesticides, } \\
\text { herbicides, water) }\end{array}$ \\
\hline $\begin{array}{l}\text { Moderate evidence } \\
\text { (S2) }\end{array}$ & $\begin{array}{l}\text { Rough partial budget } \\
\text { analysis (RP) }\end{array}$ & $\begin{array}{l}\text { Simulation Methods (SM) } \\
\text { using software or hardware }\end{array}$ & $\begin{array}{l}\text { Potential indirect } \\
\text { environmental benefits } \\
\text { (IB) }\end{array}$ \\
\hline $\begin{array}{l}\text { Some evidence } \\
\text { (S3) }\end{array}$ & $\begin{array}{l}\text { Unsubstantiated } \\
\text { reports (UR) }\end{array}$ & $\begin{array}{l}\text { Response } \\
\text { Functions (RF) }\end{array}$ & $\begin{array}{l}\text { Unsubstantiated } \\
\text { environmental benefits } \\
\text { (UB) }\end{array}$ \\
\hline $\begin{array}{l}\text { Inconclusive } \\
\text { evidence } \\
\text { (S4) }\end{array}$ & $\begin{array}{l}\text { Not } \\
\text { Applicable } \\
\text { (NA) }\end{array}$ & $\begin{array}{l}\text { Not } \\
\text { Applicable } \\
\text { (NA) }\end{array}$ & $\begin{array}{l}\text { Not } \\
\text { Applicable } \\
\text { (NA) }\end{array}$ \\
\hline
\end{tabular}

were defined by the fact that the results of the studies that clearly presented economic, agronomic or environmental benefits. The strength of evidence indicates the extent to which a study can be confident and adherence to their findings or recommendations can be safe. The assessment of studies using the above classification reflects only level of evidence regarding the economic, agronomic and environmental benefits presented by each study and cannot be considered as a critical appraisal of its value in general.

Based on this grading system, all articles have been carefully and systematically assessed for the outcome of their scientific work and the strength of their recommendations. All included studies were classified on the basis of the subgroups formulated for the expected economic, agronomic, and environmental benefits, as analyzed in detail above, and the following strength of evidence was applied as follows: (a) for the economic assessment: $S 1$ for partial substantiated budget reports; $S 2$ for rough partial budget analysis; $S 3$ for unsubstantiated reports; $S 4$ for not applicable; (b) agronomic assessment: $S 1$ for field trials with documented; $S 2$ for simulation models; $S 3$ for studies using response functions; $S 4$ for not applicable; (c) for the environmental assessment: $S 1$ for studies with documented environmental benefits; $S 2$ for studies presenting potential environmental benefits; $S 3$ for studies with unsubstantiated environmental benefits; and $S 4$ for studies not applicable to the above categories. As a result, at each study a level of evidence was assigned for each category of benefits depending on the subgroup that belongs to. To automatically assigned the strength of evidence for all the studies included a function with nested IF functions was formulated and applied, as follows:

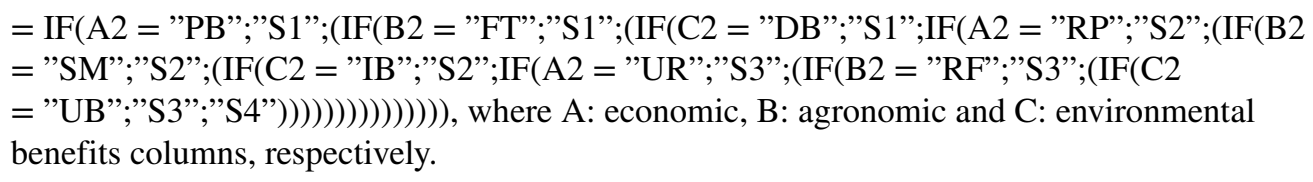

\section{Data Extraction}

A systematic search of three digital scientific journal databases (Web of Science, Scopus and Science Direct) was conducted and study characteristics from the eligible records were extracted as follows: (1) title of the published article, (2) type of publication: journal/conference/symposium, (3) year of publication, (4) origin: country/continent region, (5) design of the study, (6) type of crops. 


\section{RESULTS}

\section{Study Selection}

The first SQL query using the online tool of three online digital article sources (Scopus, Science Direct and Web of Science) gave an initial estimate of the maximum number of the studies available to be identified $(N=49.779)$. Refining the preliminary search using a more targeted SQL statement and based on search strategy of this systematic review, 83 records were finally identified $(N=48$ from Scopus, $N=19$ from Science Direct and $N=16$ from Web of Science). Study characteristics for the above studies were extracted from these three digital sources using the BibTex format (*.bib) and 80 records were imported separately into JabRef, an open source bibliography reference manager that runs on the JavaVM, where 17 records were removed as duplicates. Finally, 159 records were identified andimported into Zotero Citation Manager to check possible data gaps and update records. All records were then exported (using the csv file format) from Zotero and imported into Excel, where several pivot tables were constructed to calculate descriptive statistics and construct the corresponding charts. Finally, the systematic search of the available literaturebased on the inclusion criteria identified 108 records to be assessed for eligibility (Figure 1). All records included were assessed for eligibility and were assigned a strength of evidence with scale 1 to 4 (where S1 the strongest evidence). The assessment of the studies indicated 14 records with S3 or S4 strength of evidence and therefore these studies were excluded. Overall, there were found 94 full-text articles were identified that present benefits from the adoption of PA technologies concerning farming efficiency and environmental conservation.

Figure 1. Flowchart of article selection process
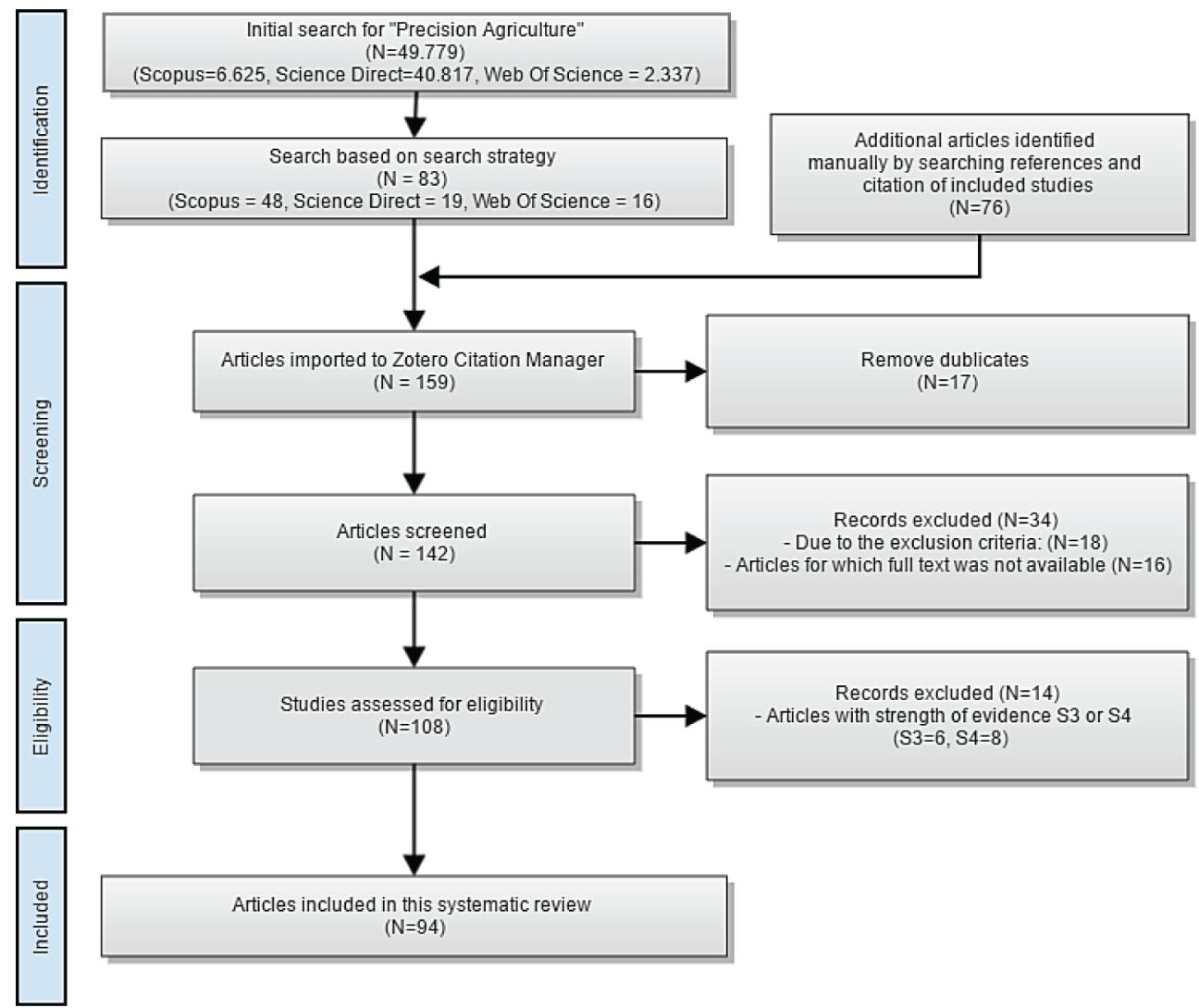


\section{Study Characteristics}

All selected studies were examined in detail and their characteristics, such as title, authors, country, PA technology used, type of economic, agronomic and environmental benefits (as described at Table 2) are given in the supplementary file (Table 10). The articles selected to be assessed for eligibility were analyzed based on the technology they use and assigned to application groups. The systematic review of the studies revealed different application groups of PA technologies that aim to improve farming efficiency and management and contribute to the environmental conservation. All studies selected were assigned to the following four main technology application groups that reflects direct or indirect benefits from the adoption of the corresponding PA technologies: (1) Technologies for managing spatial variability; (2) Precise nutrient applications; (3) Precise pesticide applications; (4) Guidance Systems (Table 3). Most of studies $(N=72)$ were assign to the category "Precise nutrient applications".

Almost half of studies ( $\mathrm{PB}+\mathrm{RP}, N=48)$ reported detailed information in the potential change of costs ( $\mathrm{PB}, N=13)$ or rough partial economic analysis $(\mathrm{RP}, N=35)$, while the rest (UR+NA, $N=60)$ either failed to enumerate the economic benefits or changes in costs are not mentioned. Concerning the agronomic assessment, most of studies used response functions ( $\mathrm{RF}, N=66)$ and field trials with documented agronomic benefits were only eighteen (FT, $N=18$ ). As probably expected, the environmental benefits were complex and it was difficult to be estimated. Most of the studies did not refer to any environmental benefits from PA technologies and only fourteen articles (DB $+\mathrm{IB}, N$ $=14$ ) presented documented or potential indirect benefits, mainly because of the reduced nutrients due to allocative inputs (Table 4).

To highlight the origin of the selected studies, the country of each manuscript was used and all selected studies were grouped per continent (Table 5) based on their stated country (if country information was not available then the country of the first author was used instead). It can be seen that most of the studies originate from Europe $(N=31, \mathrm{~S} 1=4$ and $\mathrm{S} 2=27)$ and North America $(N$ $=27, \mathrm{~S} 1=11$ and $\mathrm{S} 2=16$ ). While most of the studies with S2 were from Europe, studies with S1 strength of evidence originate from North America (Figure 2).

\section{Clustering PA Technologies Into Application Categories}

The studies included in the systematic review were examined and then grouped into application categories based on the precision agriculture technology they use. Four main PA application categories were identified: (1) Technologies for managing spatial variability for decision making; (2) Precise nutrient applications; (3) Precise pesticide applications; (4) Guidance Systems. These four main categories were then split into sub-categories to reveal further information on the technology used and finally all the included studies were assigned to these sub-categories (Table 6).

Table 3. Frequencies (N; \%) of the articles per application group

\begin{tabular}{|l|l|l|l|}
\hline \multicolumn{1}{|c|}{ Groups } & \multicolumn{1}{|c|}{$\begin{array}{c}\text { Frequency of Records Assessed for } \\
\text { Eligibility }\end{array}$} & $\begin{array}{l}\text { Frequency of Included } \\
\text { Studies With S1 or S2 }\end{array}$ & $\begin{array}{c}\text { \% Records } \\
\text { S1 and S2 }\end{array}$ \\
\cline { 2 - 4 } & \multicolumn{1}{|c|}{$(\boldsymbol{N}=\mathbf{1 0 8})$} & $\mathbf{9 8})$ & 63.8 \\
\hline 1. Managing spatial variability & $71(\mathrm{~S} 1=4 ; \mathrm{S} 2=56 ; \mathrm{S} 3=5 ; \mathrm{S} 4=6)$ & 60 & 26.6 \\
\hline 2. Precise nutrient applications & $27(\mathrm{~S} 1=17 ; \mathrm{S} 2=8 ; \mathrm{S} 3=1 ; \mathrm{S} 4=1)$ & 25 & 3.2 \\
\hline 3. Precise pesticide applications & $3(\mathrm{~S} 1=0 ; \mathrm{S} 2=3 ; \mathrm{S} 3=0 ; \mathrm{S} 4=0)$ & 3 & 6.4 \\
\hline $\begin{array}{l}\text { 4. Automations (Guidance } \\
\text { Systems) }\end{array}$ & $7(\mathrm{~S} 1=1 ; \mathrm{S} 2=5 ; \mathrm{S} 3=0 ; \mathrm{S} 4=1)$ & 6 & 100.0 \\
\hline Totals & 108 & 98 & \\
\hline
\end{tabular}


Table 4. Frequencies of the articles per PA technology group and assessment per strength of evidence (S1, S2, S3, S4)

\begin{tabular}{|c|c|c|c|c|c|c|}
\hline \multirow{2}{*}{\multicolumn{2}{|c|}{ Assessment }} & \multicolumn{5}{|c|}{ PA Technology Application Group } \\
\hline & & $\begin{array}{l}\text { 1. Managing } \\
\text { Spatial } \\
\text { Variability }\end{array}$ & $\begin{array}{c}\text { 2. Precise } \\
\text { Nutrient } \\
\text { Applications }\end{array}$ & $\begin{array}{l}\text { 3. Precise } \\
\text { Pesticide } \\
\text { Applications }\end{array}$ & $\begin{array}{l}\text { 4. Automations } \\
\text { Using Guidance } \\
\text { Systems }\end{array}$ & $\begin{array}{l}\text { Totals } \\
(\mathrm{N} ; \%)\end{array}$ \\
\hline \multicolumn{7}{|c|}{ Economic } \\
\hline S1 & Partial budget reports (PB) & 3 & 9 & & 1 & 13 \\
\hline $\mathrm{S} 2$ & $\begin{array}{l}\text { Rough partial budget } \\
\text { reports (RP) }\end{array}$ & 20 & 13 & & 2 & 35 \\
\hline S3 & $\begin{array}{l}\text { Unsubstantiated reports } \\
\text { (UR) }\end{array}$ & 18 & 2 & & 3 & 23 \\
\hline S4 & Not applicable (NA) & 30 & 3 & 3 & 1 & 37 \\
\hline \multicolumn{2}{|c|}{ Totals } & $71(65.7 \%)$ & $27(25.0 \%)$ & $3(2.8 \%)$ & $7(6.5 \%)$ & $108 ; 100 \%$ \\
\hline \multicolumn{7}{|c|}{ Agronomic } \\
\hline S1 & Field trials $(\mathrm{FT})$ & 2 & 15 & & 1 & 18 \\
\hline $\mathrm{S} 2$ & Simulation Methods (SM) & 6 & 4 & & 1 & 66 \\
\hline S3 & Response Functions (RF) & 53 & 7 & 3 & 3 & 11 \\
\hline $\mathrm{S} 4$ & Not applicable (NA) & 10 & 1 & & 2 & 13 \\
\hline \multicolumn{2}{|c|}{ Totals } & $71(65.7 \%)$ & $27(25.0 \%)$ & $3(2.8 \%)$ & $7(6.5 \%)$ & $108 ; 100 \%$ \\
\hline \multicolumn{7}{|c|}{ Environmental } \\
\hline S1 & Documented benefits (DB) & & 1 & & & 1 \\
\hline $\mathrm{S} 2$ & Potential indirect benefits (IB) & 10 & 3 & & & 13 \\
\hline S3 & Unsubstantiated benefits (UB) & 10 & 10 & & & 20 \\
\hline S4 & Not applicable (NA) & 51 & 13 & 3 & 7 & 74 \\
\hline \multicolumn{2}{|c|}{ Totals } & $71(65.7 \%)$ & $27(25.0 \%)$ & $3(2.8 \%)$ & $7(6.5 \%)$ & $108 ; 100 \%$ \\
\hline
\end{tabular}

Table 5. Frequencies (N; \%) of the articles per region

\begin{tabular}{|l|l|l|l|}
\hline \multicolumn{1}{|c|}{ Region of Studies } & \multicolumn{1}{|c|}{$\begin{array}{c}\text { Frequency of Records } \\
\text { Assessed for Eligibility }\end{array}$} & $\begin{array}{c}\text { Frequency of Records } \\
\text { Included With S1 or S2 }\end{array}$ & \% Records S1 and S2 \\
\hline Europe & $\begin{array}{l}37(\mathrm{~S} 1=4 ; \mathrm{S} 2=27 ; \mathrm{S} 3= \\
3 ; \mathrm{S} 4=3)\end{array}$ & 31 & 33.0 \\
\hline North America & $\begin{array}{l}29(\mathrm{~S} 1=11 ; \mathrm{S} 2=16 ; \mathrm{S} 3= \\
1 ; \mathrm{S} 4=1)\end{array}$ & 27 & 28.7 \\
\hline Asia & $\begin{array}{l}15(\mathrm{~S} 1=4 ; \mathrm{S} 2=10 ; \mathrm{S} 3= \\
0 ; \mathrm{S} 4=1)\end{array}$ & 14 & 14.9 \\
\hline Australia & $\begin{array}{l}14(\mathrm{~S} 1=1 ; \mathrm{S} 2=10 ; \mathrm{S} 3= \\
0 ; \mathrm{S} 4=3)\end{array}$ & 11 & 9.6 \\
\hline South America & $\begin{array}{l}11(\mathrm{~S} 1=2 ; \mathrm{S} 2=7 ; \mathrm{S} 3=2 ; \\
\mathrm{S} 4=0)\end{array}$ & 9 & 2.1 \\
\hline Africa & $2(\mathrm{~S} 1=0 ; \mathrm{S} 2=2 ; \mathrm{S} 3=0 ;$ & 2 & 100.0 \\
\hline Total & $\mathrm{S} 4=0)$ & 94 & \\
\hline
\end{tabular}


Figure 2. Frequency of articles per region per strength of evidence

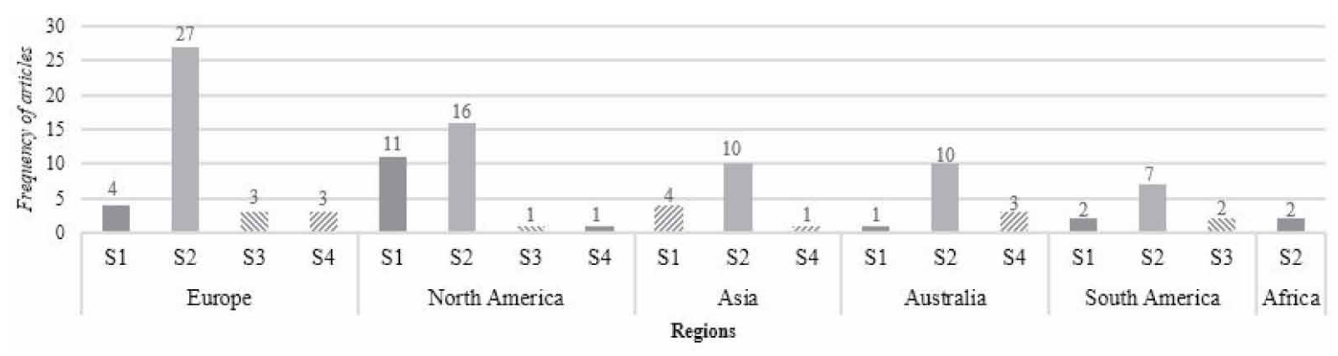

\section{Quality of Reviewed Articles}

Based on the grading system for the strength of evidence of the studies included of this systematic review, there 24 records were classified as S1, 45 records as S2, 38 records as S3 and 3 records as $\mathrm{S} 4$. A total of 34 records were excluded based on the exclusion criteria. Top three PA categories with the most records assigned were (Figure 3): (1) [1.3] Use of wireless networks $(N=16)$; (2) [2.2] Variable rate technology applications $(N=14)$ and (3) [1.6] Management of environmental sensitive areas $(N$ $=13$ records). Top three PA technologies with the most records finally included (sum of records with S1 and S2 strength of evidence) were: (1) [1.3] Use of wireless networks ( $N=14)$; (2) [2.2] Variable rate technology applications $(N=13)$; and (3) [1.6] Management of environmentally sensitive areas $(N=11)$. If we focus only on the first two categories, the category with the most articles with $\mathrm{S} 1$ ( $N$ =9) strength of evidence is "[2.2] Variable rate technology applications", while the PA technology category with the most articles included in this systematic review (S1 and S2 strength of evidence, $N=14$ ) is "[1.3] Use of wireless networks" (Figure 4).

Most studies $(N=71)$ were assigned to the category [1] "Managing spatial variability" (Figure3), which has also the most records with S1 and S2 strength of evidence: $N=60$ records. Twenty-seven $(N=27)$ studies were assigned to the second category [2] "Precise nutrient applications" $(N=28)$ with S1 and S2 strength of evidence: $N=25$ records.

The economic assessment of the articles included showed that most of the studies $(N=87)$ presented rough partial budget analysis regarding the change in costs and only few articles $(N=$ 13) provided detailed cost information (Table 5). Regarding the agronomic benefits, most of studies referred to simulation methods or hardware/equipment $(N=65)$ and similarly only few $(N=18)$ were about field trials with documented benefits (Table 7). Concerning the environmental benefits, most of studies reported unsubstantiated benefits $(N=20)$ or potential indirect benefits $(N=13)$ and only one article presented documented environmental benefits.

The results of the economic, agronomic and environmental assessment, based on the strength of evidence summarized for all the studies included in this systematic review, are given at table 7 and figure 5 .

\section{DISCUSSION}

The systematic review of the eligible articles included revealed there are at least four main PA application groups that have direct or indirect benefits and aim to improve farming efficiency and reduce production costs (Table 8): (a) managing field spatial variability; (b) performing allocative and more precise nutrient applications; (c) achieving more precise pesticide applications; and (d) provide automation solutions by using guidance systems to minimize labor costs. Adopting PA technologies for managing spatial applications are obvious helps farmers to organize sampling data make better decisions, providing also information to improve farming management. In addition, the adoption of 
Table 6. PA technologies grouped into application categories for the studies included

\begin{tabular}{|c|c|c|}
\hline PA Technologies Grouped Into Application Categories & \# & References \\
\hline 1. Managing spatial variability for decision making & 71 & \\
\hline $\begin{array}{l}\text { 1.1. Directed sampling: collecting data and monitoring } \\
\text { field-related parameters: PA provides field information } \\
\text { (i.e. weighing biomass, measuring leaf chlorophyll content, } \\
\text { weighing fruit, etc.) }\end{array}$ & 3 & $\begin{array}{l}\text { (Mesas-Carrascosa et al., 2015; Martínez et al., 2017; } \\
\text { Bramley and Janik, 2005) }\end{array}$ \\
\hline $\begin{array}{l}\text { 1.2. Geo-mapping: mapping soil type and characteristics, } \\
\text { nutrients levels or other information in layers and assign that } \\
\text { information to the field location. Use of GIS and GPS to } \\
\text { produce thematic maps. }\end{array}$ & 10 & $\begin{array}{l}\text { (Oliver et al., 2010; Palaniswami et al., 2011; Beeri and } \\
\text { Peled, 2009; Inamura et al., 2004; Mazloumzadeh et al., } \\
\text { 2010; Bier and de Souza, 2017; Moharana and Dutta, 2016; } \\
\text { Le Cointe et al., 2016; Soderstrom et al., 2016; Bramley et } \\
\text { al., 2013) }\end{array}$ \\
\hline $\begin{array}{l}\text { 1.3. Use of a wireless sensor network with GPS support: the } \\
\text { use of sensors in the fields allows a continuous monitoring } \\
\text { of soil characteristics, plant physicochemical parameters and } \\
\text { climatic conditions. The field is usually delineated using an } \\
\text { in-vehicle GPS receiver. }\end{array}$ & 16 & $\begin{array}{l}\text { (Javier Ferrandez-Pastor et al., 2016; Srbinovska et al., } \\
\text { 2015; Nikolidakis et al., 2015; Mafuta et al., 2013; Camilli } \\
\text { et al., 2007; Bogue, 2017; Bauer et al., 2016; Delibasic and } \\
\text { Pejanovic-Djurisic, 2017; Fernandes et al., 2013; Dias et al., } \\
\text { 2013; Rosell and Sanz, 2012; He et al., 2007; Moreenthaler } \\
\text { et al. 2003; Christy, 2008; Bontsema et al., 2011; Riquelme } \\
\text { et al., 2009) }\end{array}$ \\
\hline $\begin{array}{l}\text { 1.4. Proxy-detection (or proximal sensing): robots or in- } \\
\text { vehicle sensors can measure plant related parameters (i.e. leaf } \\
\text { status or plant growth stage). Ground based proximal sensors } \\
\text { mounted on agricultural machinery, can collect valuable } \\
\text { information on spatial variation within a field. }\end{array}$ & 4 & $\begin{array}{l}\text { (van Vuuren et al., 2006; Cao et al., 2017; Rossel and } \\
\text { Bouma, 2016; Wetterlind et al., 2010) }\end{array}$ \\
\hline $\begin{array}{l}\text { 1.5. Aerial or Satellite Remote Sensing (RS): use of Remote } \\
\text { Sensing images and maps. Various RS applications based on } \\
\text { these data can provide useful information for decision making }\end{array}$ & 11 & $\begin{array}{l}\text { (Candiago et al., 2015; Lyle et al., 2013; Seelan et al., 2003; } \\
\text { Conţiu and Groza, 2016; Hunt et al., 2005; Al-Gaadi et al., } \\
\text { 2016; Noori and Panda, 2016; Lyle and Ostendorf, 2011; } \\
\text { Matese et al., 2015; Kyveryga et al., 2011; Casa et al., 2012) }\end{array}$ \\
\hline $\begin{array}{l}\text { 1.6. Management of environmentally sensitive areas: PA } \\
\text { technologies provide information by calculating greenhouse } \\
\text { gas emissions due to mechanized operations and therefore } \\
\text { they can indirectly limit emissions to the environment. They } \\
\text { can also lead to higher marginal abatement costs in the form } \\
\text { of forgone profits. }\end{array}$ & 13 & $\begin{array}{l}\text { (Schieffer and Dillon, 2015; Shaw et al., 2016; Cordoba } \\
\text { et al., 2016; McConnell and Burger, 2011; Bramley et al., } \\
\text { 2008; Stull et al., 2004; Schemberger et al., 2017; Kassam } \\
\text { and Brammer, 2016; Garibaldi et al., 2017; Cambouris et } \\
\text { al., 2014; Hoffmann et al., 2017; Lobell and Azzari, 2017; } \\
\text { Kalluri et al. 2003) }\end{array}$ \\
\hline $\begin{array}{l}\text { 1.7. Profitability maps: Mapped yield data combined with } \\
\text { overlaid actual farm-level costs can convert yield maps into } \\
\text { profitability maps. }\end{array}$ & 1 & (Bazzi et al., 2015) \\
\hline 1.8. Divert animal intrusion (in the agricultural lands) & 1 & (Bapat et al., 2017) \\
\hline $\begin{array}{l}\text { 1.9. Economic/Comparative Analysis for decision making: } \\
\text { Economic analysis using PA technologies or comparative } \\
\text { analysis of previous case studies. }\end{array}$ & 12 & $\begin{array}{l}\text { (Silva et al., 2007; Melo Dematte et al., 2014; Bramley, } \\
\text { 2009; Jochinke et al., 2007; Liu et al., 2017; Nawar et al., } \\
\text { 2017; Bachmaier and Gandorfer, 2009; Zude-Sasse et al., } \\
\text { 2016; Bora et al., 2012; Rickard, 2015; Schellberg et al., } \\
\text { 2008; Plant, 2001) }\end{array}$ \\
\hline 2. Precise nutrient applications & 27 & \\
\hline $\begin{array}{l}\text { 2.1 Allocate inputs: soil/yield maps can be used to alter } \\
\text { fertilizer applications to suit current soil's characteristics. Soil } \\
\text { maps can also be used to alter irrigation plans. }\end{array}$ & 9 & $\begin{array}{l}\text { (Bryan et al., 2011; Mitralexis and Goumopoulos, 2015; } \\
\text { Sadler et al., 2005; Biermacher et al., 2006; Krell et al., } \\
\text { 2003; Timmermann et al., 2003; Jayakumar et al., 2017; } \\
\text { Parihar et al., 2017; Devkota et al., 2016) }\end{array}$ \\
\hline $\begin{array}{l}2.2 \text { Variable Rate Technology (VRT): variable rate application } \\
\text { of inputs, based on soil properties, can increase yield and } \\
\text { reduce costs. With PA technologies, a better allocative inputs } \\
\text { plan can be applied instead of the average rate of inputs based } \\
\text { on farmer's knowledge and experience. }\end{array}$ & 14 & $\begin{array}{l}\text { (Havlin and Heiniger, 2009; Maine et al., 2010; } \\
\text { Schimmelpfennig and Ebel, 2016; Basso et al., 2011; Tekin, } \\
\text { 2010; Robertson et al., 2009; West and Kovacs, 2017; } \\
\text { Pahlmann et al., 2017; Boyer et al., 2011; Johnson and } \\
\text { Richard, 2010; Biermacher et al., 2009; Panagopoulos et al., } \\
\text { 2014; Yang et al. 2012; Lawes and Robertson, 2011) }\end{array}$ \\
\hline $\begin{array}{l}2.3 \text { Zone management }(\mathrm{ZM}) \text { : yield monitoring with } \\
\text { determination of productivity zones or poor fertility zones/ } \\
\text { zones prone to diseases }\end{array}$ & 4 & $\begin{array}{l}\text { (Basso et al., 2011; Zandonadi et al., 2013; Robertson et al., } \\
\text { 2007; Robertson et al., 2008) }\end{array}$ \\
\hline
\end{tabular}


Table 6. Continued

\begin{tabular}{|c|c|c|}
\hline PA Technologies Grouped Into Application Categories & $\#$ & References \\
\hline 3. Precise pesticide applications & 3 & \\
\hline $\begin{array}{l}\text { 3.1. Light bar guidance systems: Light bar guidance systems } \\
\text { are relatively inexpensive guidance systems and they provide } \\
\text { an easy way to guide equipment across a field to prevent } \\
\text { overlapping when spraying pesticides. }\end{array}$ & & \\
\hline $\begin{array}{l}\text { 3.2. Unmanned aerial vehicles (UAV), use of robots (for weed } \\
\text { control), automatic boom }\end{array}$ & 3 & $\begin{array}{l}\text { (Zavala-Yoe et al., 2017; Sabanci and Aydin, 2017; Berge et } \\
\text { al., 2012) }\end{array}$ \\
\hline 4. Automation using Guidance Systems & 7 & \\
\hline $\begin{array}{l}\text { 4.1. Automated steering systems: autosteer systems can reduce } \\
\text { the number of overlaps tractors make across the land using } \\
\text { GPS. Auto pilot guidance systems installed on tractors can } \\
\text { also reduce fatigue and labor costs and can expand hours of } \\
\text { operation. Autosteer can also reduce the skill level required to } \\
\text { operate farm machinery. }\end{array}$ & 6 & $\begin{array}{l}\text { (Shockley et al., 2011; Edwards et al., 2017; D’Antoni et al., } \\
\text { 2012; Oberthür et al., 2007; Lamb et al., 2008; Schuster et } \\
\text { al., 2011) }\end{array}$ \\
\hline 4.2. Automations for agronomical practices & 1 & (Kroulík et al., 2011) \\
\hline
\end{tabular}

Figure 3. Strength of evidence for selected articles per PA technology category. Strength of Evidence: (a) strong evidence (S1); (b) moderate evidence (S2); (c) some evidence (S3); (d) inconclusive evidence (S4), PA technology categories: 1. Technologies for managing spatial variability for decision making: [1.1] Directed sampling; [1.2] Geo-mapping, [1.3] Use of wireless sensor networks; [1.4] Proxy-detection; [1.5] Aerial or Satellite Remote Sensing; [1.6] Management of environmentally sensitive areas; [1.7] Profitability maps; [1.8] Divert animal intrusion; [1.9] Economic/Comparative Analysis for decision making, 2. Precise nutrient applications: [2.1] Allocate inputs; [2.2] Variable rate Technology (VRT); [2.3] Zone management, 3. Precise pesticide applications: [3.1] Light bar guidance systems; [3.2] Unmanned aerial vehicles or robots, 4. Automation using Guidance Systems: [4.1] Automated steering systems; [4.2] Automations for agronomical practices.

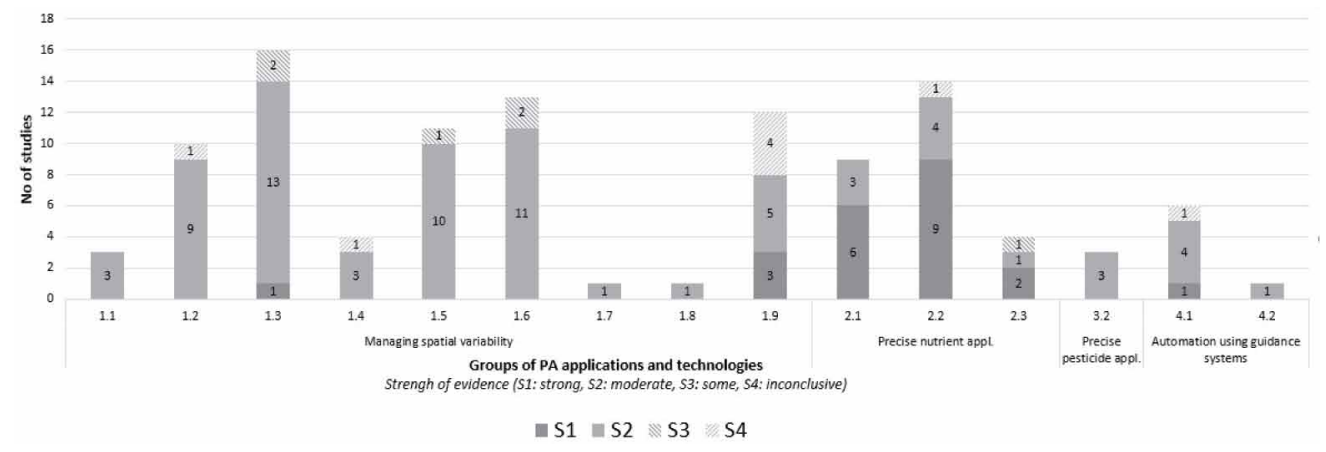

PA technologies can reduce the environmental impact of the agronomical practices by allocating and minimizing inputs, reducing tractor laps and gas emissions from mechanized operations.

Analyzing sampling data using remote sensing techniques and spatial analysis with GPS/GIS maps may reveal problems or opportunities that farmer was not aware. Spatial analysis based on sampling data can help to improve the management of low-yielding patches or the environmentally sensitive areas. PA technologies for managing spatial variability have indirect benefits, however the studies included in this systematic review indicated that they offer critical information to improve farming efficiency and environmental conservation. Additionally, these technologies offer the ability to store and process more and more data after each cropping season. As more data is added, further information is available to draw more precise conclusions and make better decisions. In some case substantiated economic analysis or comparative analysis may be also helpful for decision making. 
Figure 4. Quality of articles included in the systematic review per precision agriculture technology used

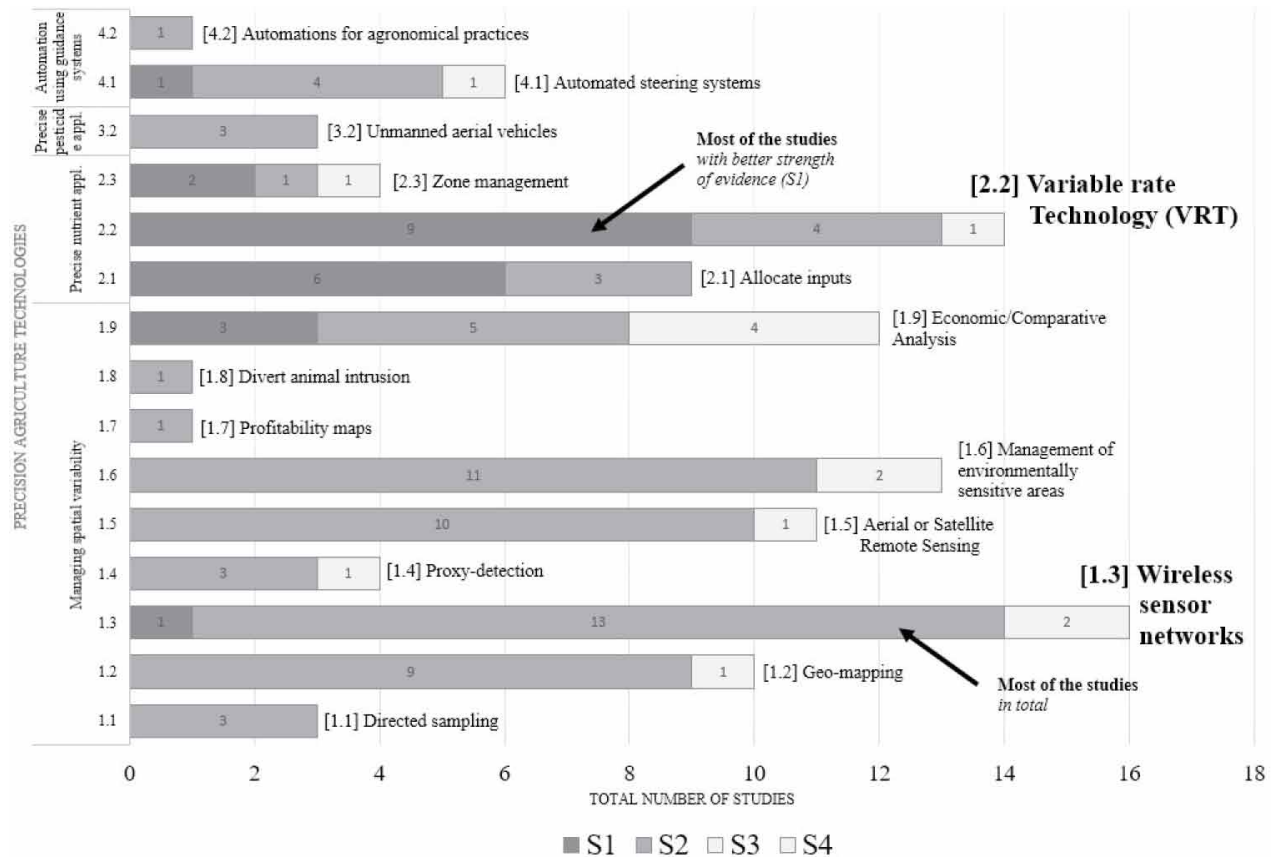

Table 7. Frequencies $(\mathrm{N} ; \%)$ of the articles per strength of evidence and assessment of studies

\begin{tabular}{|c|c|c|c|c|c|}
\hline Assessment & $\begin{array}{l}\text { Strong } \\
\text { Evidence } \\
\text { (S1) }\end{array}$ & $\begin{array}{l}\text { Moderate } \\
\text { Evidence } \\
\text { (S2) }\end{array}$ & $\begin{array}{c}\text { Some } \\
\text { Evidence } \\
\text { (S3) }\end{array}$ & $\begin{array}{l}\text { Inconclusive } \\
\text { Evidence } \\
\text { (S4) }\end{array}$ & $\begin{array}{l}\text { Totals } \\
\text { (N; \%) }\end{array}$ \\
\hline \multicolumn{6}{|l|}{ Economic } \\
\hline Partial budget reports (PB) & 13 & & & & 13 \\
\hline Rough partial budget reports (RP) & 9 & 26 & & & 35 \\
\hline Unsubstantiated reports (UR) & & 21 & 2 & & 23 \\
\hline Not applicable (NA) & & 25 & 4 & 8 & 37 \\
\hline Totals & $22(20.4 \%)$ & $72(66.7 \%)$ & $6(5.6 \%)$ & $8(7.4 \%)$ & $108 ; 100 \%$ \\
\hline \multicolumn{6}{|l|}{ Agronomic } \\
\hline Field trials (FT) & 18 & & & & 18 \\
\hline Simulation Methods (SM) & 1 & 65 & & & 66 \\
\hline Response Functions (RF) & 3 & 4 & 4 & & 11 \\
\hline Not applicable (NA) & & 3 & 2 & 8 & 13 \\
\hline Totals & $22(20.4 \%)$ & $72(66.7 \%)$ & $6(5.6 \%)$ & $8(7.4 \%)$ & $108 ; 100 \%$ \\
\hline \multicolumn{6}{|l|}{ Environmental } \\
\hline Documented benefits (DB) & 1 & & & & 1 \\
\hline Potential indirect benefits (IB) & 2 & 11 & & & 13 \\
\hline Unsubstantiated benefits (UB) & 11 & 8 & 1 & & 20 \\
\hline Not applicable (NA) & 8 & 53 & 5 & 8 & 74 \\
\hline Totals & $22(20.4 \%)$ & $72(66.7 \%)$ & $6(5.6 \%)$ & $8(7.4 \%)$ & $108 ; 100 \%$ \\
\hline
\end{tabular}


Figure 5. Frequency of articles per strength of evidence for the economic, agronomic and environmental assessment

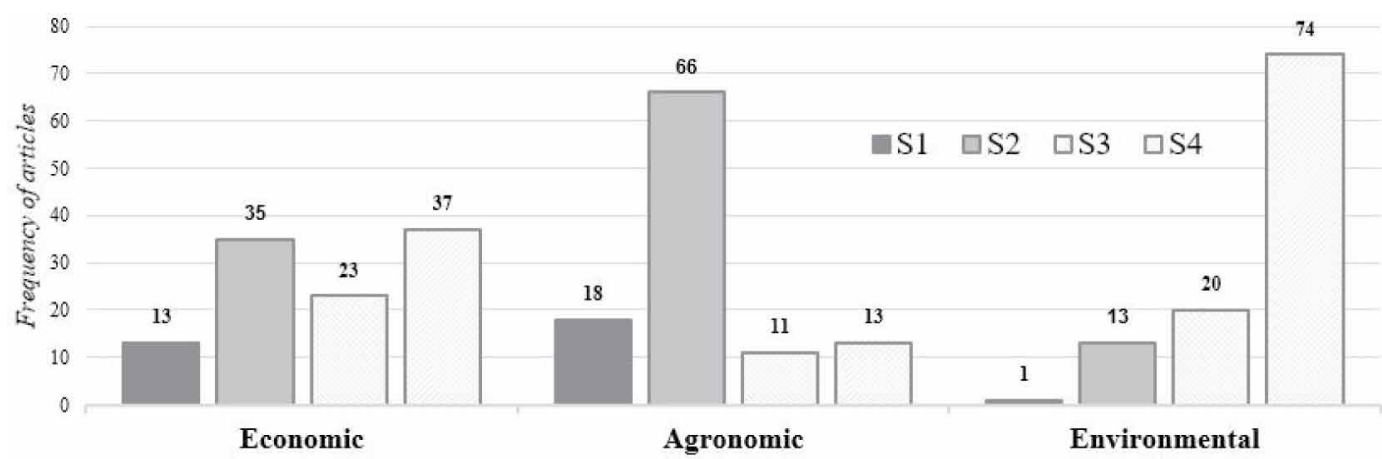

Table 8. Type of benefits from the adoption of PA technologies

\begin{tabular}{|l|l|}
\hline \multicolumn{1}{|c|}{ Application Groups } & \multicolumn{1}{c|}{ Type of Benefits } \\
\hline 1. Managing spatial variability & $\begin{array}{l}\text { Indirect benefits from sampling data information for the state of crops. Organized } \\
\text { data provide information for better decision making. }\end{array}$ \\
\hline 2. Precise nutrient applications & $\begin{array}{l}\text { Direct economic and environmental benefits from reduced or targeted placement of } \\
\text { crop inputs such as nutrients and water. }\end{array}$ \\
\hline 3. Precise pesticide applications & $\begin{array}{l}\text { Direct economic and environmental benefits from the reduced or targeted use of } \\
\text { pesticides using automated systems. }\end{array}$ \\
\hline $\begin{array}{l}\text { 4. Automations using Guidance } \\
\text { Systems }\end{array}$ & $\begin{array}{l}\text { Direct economic benefits from using automated unmanned systems (reduced } \\
\text { labor costs) and reduced impact on the environment (reduction of machinery pass } \\
\text { frequency and reduction of soil compaction). }\end{array}$ \\
\hline
\end{tabular}

Adopting PA technologies for more precise nutrient applications can have direct benefits from reducing the crop input costs (controlled amount and targeted application of nutrients and water). Reducing the amount of inputs can also have an environmental benefit because less unused nutrients that end up to ecosystems and the environment through leaching of water-soluble nitrates, emissions and runoff. Precise nutrient applications can help maximize potential yield and minimize environmental risk, based on detailed information sampled on farm fertility levels or low-yield soil patches, soil types and environmental sensitivity or the areas. Targeted nutrient applications may also reduce the number of trips needed by applying at first a blend of nutrients ( $\mathrm{N}$ and either $\mathrm{P}$ or $\mathrm{K})$ that best matches the required ratio of these nutrients and then make one final pass to spot apply the third nutrient to areas that they are deficient in it.Similar to the precise nutrient applications, precise pesticide applications aim to deliver the amount of pesticide needed. The analysis of the studies included in this systematic review showed that automated robots can be very promising to apply more targeted variable rate pesticides for weed control, while light bar guidance systems can be a quicker and less expensive way to guide equipment across a field, preventing overlapping when spreading pesticides.

Using guidance systems can also have direct benefits according to the studies being analyzed. In line with other studies (Cordesses et al., 2000; Debain et al., 2000; Dunn et al., 2006; Han et al., 2004, Stoll \& Kutzbach, 2000) current analysis confirms that the use of guidance systems can have many direct benefits, such as: (1) management of driver fatigue by reducing human effort associated with maintaining accurate vehicle paths; (2) reduction in operating costs because of the increased accuracy that minimizes tractor passes in the field; (3) increase in productivity by achieving higher tractor operating speeds; (4) improved quality; (5) improved human safety conditions; (6) reduced 
environmental impact (reduced carbon footprint) by reducing machinery pass frequency); (7) working regardless weather conditions.

Regarding the strength of evidence of the articles $(N=108$ in total $)$, the included studies $(N=$ 94) were assigned as having $\mathrm{S} 1(N=22$ or $20.4 \%)$ or $\mathrm{S} 2(N=72$ or $66.7 \%)$ strength of evidence and the excluded studies $\mathrm{S} 3(N=6$ or $5.6 \%)$ or $\mathrm{S} 4(N=8$ or $7.4 \%)$. Detailed benefits as were reported studies having S1 strength of evidence are given at Table 9 (in the supplementary material).

The assessment of the articles included in this systematic review revealed that there are more studies presenting tangible agronomic benefits contrary to economic or environmental benefits (Figure 5): there are 84 out of the 108 studies included having $\mathrm{S} 1(N=18)$ or $\mathrm{S} 2(N=66)$ strength of evidence. Studies presenting economic benefits are almost half: there are 48 out of the 108 studies included having $\mathrm{S} 1(N=13)$ or $\mathrm{S} 2(N=35)$ strength of evidence, suggesting that reducing costs cannot always be measurable. Unfortunately, only a small number of studies present clear and measurable environmental benefits: there are only 14 out of 108 studies included having $\mathrm{S} 1(N=1)$ or $\mathrm{S} 2(N=$ 13) strength of evidence.

Despite the fact that most of the studies (total $N=94$ or $87.1 \%$ ) were assigned a high level of evidence (S1: $N=22$ or $20.4 \%$ or S2: $N=72$ or $66.7 \%$ ), the heterogeneity of the studies did not allow to draw a general conclusion or define a confirmed monetary benefit (per PA technology used or per ha). Based on the detailed benefits reported at the included articles it can be concluded that it is still very difficult to decide whether the benefits from the adoption of a specific PA technology would be same in another situation under different criteria or factors involved.

\section{LIMITATIONS OF THIS REVIEW}

In this systematic review, only English written studies were identified. Based on the exclusion criteria any non-English written article, study or report presenting technology innovations not directly related with the adoption of precision agriculture technologies was excluded. There are also many unpublished peer-reviewed studies or studies, sent to be published, presenting positive results compared to those presenting negatives that may never reach the publication stage. It is well-known that many authors are reluctant to send their research work for publication if the findings are negative or the results are contrary to the expected ones. In addition, some studies may have probably been missed out although an extensive literature search was performed. All the above cases may introduce bias in this systematic review. Finally, it should be noted, that changing the search terms or the search strategy may lead to identification of different studies that may have also different strength of evidence.

\section{CONCLUSION}

In this systematic review, twenty-two articles were assessed as having S1 strength of evidence (20.4\%) and seventy-two as having S2 (66.7\%) strength of evidence (total $N=94$ out of the total studies assessed $(N=108$ or $87.1 \%)$. The excluded articles based on the exclusion criteria and strategy set were the articles having S3 $(\mathrm{N}=6$ or $5.6 \%)$ and $\mathrm{S} 4(\mathrm{~N}=8$ or $7.4 \%)$ strength of evidence. As a result, almost half of the studies were assessed as having S1 or S2 strength of evidence (total $N=44$ out of 108).

In most of the studies economic, agronomic and environmental benefits were reported but analyzing the gains further it was proved difficult to draw conclusions. Regarding the assessment of studies included in this systematic review towards their strength of evidence for each category of benefits (economic, agronomic and environmental), it is noted that only 22 out of the 94 articles included (S1: $N=13$ and S2: $N=9$ studies) succeeded in reporting monetary gains from the adoption of PA technologies. Similarly, a total of 19 out of the 94 articles included (S1: $N=18$ and S2: $N=$ 1 studies) reported tangible agronomic benefits. Unfortunately, most of the reports assessed failed to report measurable environmental benefits and only three studies attempted to enumerate the 
expected benefits (S1: $N=1$ and $\mathrm{S} 2: N=2$ studies), proving that it is still difficult to calculate the environmental gains from the adoption of technological innovations in agriculture.

This synthetic work revealed also that PA technologies with expected economic, agronomic and environmental benefits can be grouped into four main categories (Table 8): (1) Managing spatial variability; (2) Precise nutrient applications; (3) Precise pesticide applications; and (4) Automations using Guidance Systems. For each group different type (direct or indirect) of benefits should be expected (Table 8). In some cases, the benefits of implementing PA technologies can provide direct and tangible benefits (allocative inputs via managing spatial variability, reduced and targeted crop inputs via variable rate applications or lower labor costs due to automations using guidance systems) that can be expressed as a monetary value gain. However, there are many other cases where the adoption of PA technologies can have indirect benefits difficult to estimate their monetary value gain at first. In that way, a steady stream of farming data using sensors, drones or other technological innovations may have indirect benefits but it can be used to increase field knowledge and help to positive allocative of nutrients, water and fertilizers to reduce productivity costs and increase farming efficiency.

The findings of this systematic review can be summarized as follows:

- All studies included in the systematic review reported positive implications;

- Most of the included studies reported benefits from the adoption of PA Technologies for managing the spatial variability and the precise nutrient applications;

- Based on the strength of evidence of the included articles, the agronomic benefits are more tangible, while the economic benefits cannot always be measurable and the environmental benefits are not always clear;

- Studies with more detailed information in the change of costs were about 'precise nutrient applications';

- The heterogeneity of the studies included does not allow to make comparisons or meta-analysis or draw conclusions for future applications;

- More recent and well-designed studies of high quality focusing on measuring the benefits from adopting technology innovations in agriculture are needed;

- Results from individual case studies, even when they present tangible benefits, they cannot be generalized due to their heterogeneity.

This systematic review attempts to present the current state of the expected economic, agronomic and environmental benefits from the adoption of different PA technologies. Through a typical review process, a total number of 108 articles were thoroughly examined and almost half of them provided evidence on the effectiveness of adopting PA advanced technologies to improve farming efficiency, while reducing costs and environmental risk. However, due to the heterogeneity of the studies, it is difficult to draw a generally consensual conclusion and it seems that more work is needed to fully evaluate scientifically the efficiency of these technologies in delivering economic, agronomic, and environmental benefits in agriculture.

References of the 108 studies included in this systematic review, characteristics of studies, and the quality assessment are given in the supplementary material. 


\section{REFERENCES}

Awan, S. (2016). A review of the past and future of PA in the UK. Research review No. 87. Agriculture and Horticulture Development Board. Stoneleigh Park, Kenilworth.

Basso, B., Ritchie, J. T., Cammarano, D., \& Sartori, L. (2011). A strategic and tactical management approach to select optimal $\mathrm{N}$ fertilizer rates for wheat in a spatially variable field. European Journal of Agronomy, 35(4), 215-222. doi:10.1016/j.eja.2011.06.004

Baudron, F., Giller, K.E., (2014). Agriculture and nature: trouble and strife? Biological Conservation, 170, 232-245. Retrieved January 13, 2018. doi:10.1016/j.biocon.2013.12.009

Boyer, C. N., Wade, B., Solie, J. B., \& Raun, W. R. (2011). Profitability of variable rate nitrogen application in wheat production. Precision Agriculture, 12(4), 473-487. doi:10.1007/s11119-010-9190-5

Calegari, F., Tassi, D., \& Vincini, M. (2013). Economic and environmental benefits of using a spray control system for the distribution of pesticides. Journal of Agricultural Engineering, 44(2s), 163-165. doi:10.4081/ jae.2013.274

Castle, M. H., Lubben, B. D., \& Luck, J. D. (2016). Factors Influencing the Adoption of PA Technologies by Nebraska Producers. Presentations, Working Papers, and Gray Literature: Agricultural Economics. Retrieved January 13, 2018, from http://digitalcommons.unl.edu/ageconworkpap/49

Cordesses, L., Cariou, C., \& Berducat, M. (2000). Combine harvester control using real time kinematic GPS. Precision Agriculture, 2(2), 147-161. doi:10.1023/A:1011473630247

Daberkow, S. G., \& McBride, W. D. (2003). Farm and Operator Characteristics Affecting the Awareness and Adoption of PA Technologies in the US. Precision Agriculture, 4(2), 163-177. doi:10.1023/A:1024557205871

Debain, C., Chateau, T., Berducat, M., Martinet, P., \& Bonton, P. (2000). A guidance-assistance system for agricultural vehicles. Computers and Electronics in Agriculture, 25(1-2), 29-51. doi:10.1016/S01681699(99)00054-X

Dunn, P. K., Powierski, A. P., \& Hill, R. (2006). Statistical evaluation of data from tractor guidance systems. Precision Agriculture, 7(3), 179-192. doi:10.1007/s11119-006-9007-8

Fleming, K. L., Heermann, D. F., \& Westfall, D. G. (2004). Evaluating soil color with farmer input and apparent soil electrical conductivity for management zone delineation. Agronomy Journal, 96(6), 1581-1587. doi:10.2134/ agronj2004.1581

Foley, J., Ramankutty, N., Brauman, K., Cassidy, E.S., Gerber, J.S., Johnston, M., ... Zaks, D.P.M. (2011). Solutions for a cultivated planet. Nature, 478, 337-342.

Follett, R. F., \& Delgado, J. A. (2002). Nitrogen fate and transport in agricultural systems. Journal of Soil and Water Conservation, 57, 402-408.

Han, S., Zhang, Q., Ni, B., \& Reid, J. F. (2004). A guidance directrix approach to vision-based vehicle guidance systems. Computers and Electronics in Agriculture, 43(3), 179-195. doi:10.1016/j.compag.2004.01.007

Hyytiainen, K., Niemi, J. K., Koikkalainen, K., Palosuo, T., \& Salo, T. (2011). Adaptive optimization of crop production and nitrogen leaching abatement under yield uncertainty. Agricultural Systems, 104(8), 634-644. doi:10.1016/j.agsy.2011.06.006

Jayakumar, M., Janapriya, S., \& Surendran, U. (2017). Effect of drip fertigation and polythene mulching on growth and productivity of coconut (Cocos nucifera L.), water, nutrient use efficiency and economic benefits. Agricultural Water Management, 182, 87-93. doi:10.1016/j.agwat.2016.12.012

Kalluri, S., Gilruth, P., \& Bergman, R. (2003). The potential of remote sensing data for decision makers at the state, local and tribal level: Experiences from NASA's Synergy program. Environmental Science \& Policy, 6(6), 487-500. doi:10.1016/j.envsci.2003.08.002

Liu, Y., Langemeier, M. R., Small, I. M., Joseph, L., \& Fry, W. E. (2017). Risk Management Strategies using PA Technology to Manage Potato Late Blight. Agronomy Journal, 109(2), 562-575. doi:10.2134/agronj2016.07.0418 
Meisinger, J. J., \& Delgado, J. A. (2002). Principles for managing nitrogen leaching. Journal of Soil and Water Conservation, 57, 485-498.

Nawar, S., Corstanje, R., Halcro, G., Mulla, D., \& Mouazen, A. M. (2017). Delineation of Soil Management Zones for Variable-Rate Fertilization: A Review. Advances in Agronomy, 143, 175-245. doi:10.1016/ bs.agron.2017.01.003

Panagopoulos, Y., Makropoulos, C., Gkiokas, A., Kossida, M., Evangelou, L., Lourmas, G., \& Mimikou, M. et al. (2014). Assessing the cost-effectiveness of irrigation water management practices in water stressed agricultural catchments: The case of Pinios. Agricultural Water Management, 139, 31-42. doi:10.1016/j.agwat.2014.03.010

Pierpaoli, E., Carli, G., Pignatti, E., \& Canavari, M. (2013). Drivers of PA technologies adoption: A literature review. Procedia Technology, 8, 61-69. doi:10.1016/j.protcy.2013.11.010

Prisma. (2009). Flow Diagram, Transparent reporting of Systematic Reviews and Meta-Analysis. Retrieved January 13, 2018, from http://prisma-statement.org/documents/PRISMA\%202009\%20flow\%20diagram.pdf

Robertson, M. J., Lewellyn, R. S., Mandel, R., Lawes, R., Bramley, V., Swift, L., \& O'Callaghan, C. et al. (2012). Adoption of variable rate fertiliser application in the Australian grains industry: status, issues and prospects. Precision Agriculture, 13(2), 181-199. doi:10.1007/s11119-011-9236-3

Rodriguez, H. G., Popp, J., Gbur, E., \& Chaubey, I. (2011). Environmental and economic impacts of reducing total phosphorous runoff in an agricultural watershed. Agricultural Systems, 104(8), 623-633. doi:10.1016/j. agsy.2011.06.005

Srinivasan, A. (2006). Handbook of Precision Agriculture. Boca Raton: CRC Press.

Stafford, J. V. (2000). Implementing PA in the 21st Century. Journal of Agricultural Engineering Research, 76, 267-275. doi:10.1006/jaer.2000.0577

Stoll, A., \& Kutzbach, H. D. (2000). Guidance of a forage harvester with GPS. Precision Agriculture, 2(3), 281-291. doi:10.1023/A:1011842907397

Tey, Y. S., \& Brindal, M. (2012). Factors Influencing the Adoption of Precision Agricultural Technologies: A Review for Policy Implications. Precision Agriculture, 13(6), 713-730. doi:10.1007/s11119-012-9273-6

van der Windt, D. A. W. M., Thomas, E., Pope, D. P., de Winter, A. F., Macfarlane, G. J., Bouter, L. M., \& Silman, A. J. (2000). Occupational risk factors for shoulder pain: A systematic review. Journal of Occupational and Environmental Medicine, 57(7), 433-442. doi:10.1136/oem.57.7.433 PMID:10854494

Vrindts, E., Mouazen, A. M., Reyniers, M., Maertens, K., Maleki, M. R., Ramon, H., \& De Baerdemaeker, J. (2005). Management zones based on correlation between soil compaction, yield and crop data. Biosystems Engineering, 92(4), 419-428. doi:10.1016/j.biosystemseng.2005.08.010

West, G. H., \& Kovacs, K. (2017). Addressing Groundwater Declines with Precision Agriculture: An Economic Comparison of Monitoring Methods for Variable-Rate Irrigation. Water (Basel), 9(1), 28. doi:10.3390/w9010028

Thomas Koutsos is Laboratory Teaching Staff at the School of Agriculture, Faculty of Agriculture, Forestry, and Natural Environment. His research interests include environment protection and management of environmental impacts, applied and environmental geology, geographical information systems and spatial data analysis, biodiversity and sustainable development, waste management, computer networks, database management and SQL programming, statistical software and data analysis of experimental data. He has published in many scientific journals and conference proceedings and has participated in 8 funded research projects.

George Menexes is Assistant Professor of biometry and agricultural experimentation at the School of Agriculture, Faculty of Agriculture, Forestry, and Natural Environment. His research interests include the statistical analysis of data from biological science, research methodology, multidimensional and multivariate data analysis methods for categorical and quantitative data. He has published more than 120 papers in scientific journals and conference proceedings and has participated in 26 funded research projects. 